\title{
Mechanisms of autobiographical memory retrieval in younger and older adults
}

\author{
KATINKA DIJKSTRA \\ Florida State University, Tallahassee, Florida \\ and \\ BARBARA KAUP \\ Technical University of Berlin, Berlin, Germany
}

\begin{abstract}
In this study, retrieval of autobiographical memories was compared within or without the context of a lifetime period and between younger and older adults. The results of two experiments demonstrated that memories were more accessible for younger and older adults when they were retrieved within a time period context than without such context. However, when the retrieval context was more constrained and limited to cue word memories, the benefit of retrieval context disappeared. The results also suggested that as compared with younger adults, older adults were more likely to selectively retain memories with distinctive characteristics, such as being self-relevant and emotionally intense, particularly when remote memories were involved. Mechanisms of autobiographical memory retrieval in younger and older adults.
\end{abstract}

When asked to report an eventful memory, a 74-yearold might answer, "I remember in 1974 the day my wife and I signed a lease in a major shopping center." Would responding to this task be easier if this person had previously described a period in his life during which he had ventured into a new business? Or would it be easier for him to retrieve a memory in response to this task without such a context? Also, do the memories elicited by a task such as this differ in their properties, depending on whether the participant is a younger or an older adult? Are the memories reported by older adults possibly characterized by more distinctive properties than the ones reported by younger adults, reflecting a selective retention mechanism utilized by older adults by which mainly those memories are kept accessible that stand out, relative to others? The present article addresses both of these questions.

According to a model of autobiographical memory, memories such as the one above about signing the lease are organized in a hierarchy with lifetime periods at the top, followed by general events and specific events lower in the hierarchy (Conway, 1992; Conway \& PleydellPearce, 2000). Access to specific events would be facilitated according to this model when retrieval takes place within the context of a lifetime period, because this life-

The authors thank Colleen Kelley, Charles P. Thompson, Rolf Zwaan, and an anonymous reviewer for their feedback on an earlier draft of the manuscript. The authors also acknowledge Brittney Dodson, Asmite Gherezgiher, Antonio Gonzalez, Pete Jamieson, Marissa Mainwood, Christine Morris, Alvaro Ortiz, Nickesha Pitter, Carol Rodrigues, Michelle Segal, Adam Summeralls, and Rebecca Thompson for their contribution to data collection and analysis. Correspondence concerning this article should be sent to K. Dijkstra, Department of Psychology and Pepper Institute on Aging and Public Policy, Florida State University, Tallahassee, FL 32306-1270 (e-mail: dijkstra@psy.fsu.edu). time period provides a retrieval context of autobiographical information along temporal and thematic dimensions that enables a more direct search of events than when no such context is present (Burt, Kemp, \& Conway, 2003).

To illustrate, a lifetime period could be WWII. A general event within this period would be for a soldier to fight in the Battle of the Bulge, whereas a specific event could be for this soldier to jump in a ditch during an air raid for safety and break his nose when going in face first and landing on his rifle.

Several studies have been performed investigate whether particular retrieval contexts facilitate autobiographical memory retrieval (e.g., Reiser, Black, \& Abelson, 1985). However, to date, only one study has been performed to examine in particular whether lifetime periods as retrieval contexts facilitate access to autobiographical memories, as is predicted by the model advocated by Conway (1992; Conway \& Pleydell-Pearce, 2000). In this study, Conway and Bekerian (1987) tested whether prior presentation of a phrase naming a lifetime period (e.g., elementary school) would facilitate autobiographical memory retrieval to a related cue from the participant's personal history, which named a general event (e.g., holiday in Italy), as compared with a neutral prime presented prior to this personal history cue (ready). The results of their Experiments 2 and 3 showed that personal primes based on lifetime contexts, when combined with a cue naming a detail of the participant's personal history, led to faster access to specific autobiographical events than when the prime was neutral. Thus, the results of this study provide support for Conway's model of hierarchical organization of autobiographical memories.

However, the generalizability of Conway and Bekerian's (1987) findings may be limited by certain procedural 
components in their experiments. First, as the authors themselves noted (p. 129), it was unclear whether the primed lifetime periods described an activity (i.e., going to elementary school), a time-based context for the activity (i.e., elementary school), or both, which complicates the interpretation of the results. The first case describes a situation-specific context, whereas the second case describes a more general time-specific context. In order to assess the benefits of lifetime contexts on memory retrieval, one would need to define time-based retrieval contexts that are clearly different from activities and, as far as the temporal extension is concerned, at the same general level in the proposed hierarchy as lifetime periods are.

Second, lifetime periods (e.g., college years) were used as retrieval contexts in connection to personal history cues (e.g., my first soccer team) that the participants themselves had specified as being related to the respective lifetime periods 4-7 months earlier. Thus, lifetime periods and personal history cues were necessarily associated. The question arises as to whether lifetime periods per se constituted effective retrieval cues for autobiographical information or, alternatively, whether lifetime periods simply preactivated the personal history cues and, thereby, facilitated subsequent memory retrieval to this cue.

Another question is whether the context of a lifetime period facilitates memory retrieval even under conditions in which the participant is free to choose any memory, instead of having to select a memory that is related to an additional cue. One would need to investigate the facilitating effect of lifetime periods as retrieval contexts without utilizing personal history cues to prompt memory retrieval to assess a pure context effect. Finding a facilitating effect on memory retrieval under the free choice condition would further strengthen the notion that lifetime periods, in and of themselves, constitute effective cues for autobiographical memory retrieval.

Finally, both Conway and Bekerian's (1987) study and Reiser et al.'s (1985) study were conducted on younger adults only, who had relatively easy access to relatively recent memories. Memory retrieval by other groups of participants for whom memory retrieval may be more effortful, such as older adults, should be examined in order to generalize the earlier findings and specify the benefits of more closely defined retrieval contexts.

In the present study, we examine the facilitation effects of context on autobiographical memory retrieval, using a procedure that makes possible a generalization of the findings in previous studies by including both younger and older adults. Retrieval context was assessed by utilizing two lifetime periods, an eventful and a noneventful period, in a context-no-context manipulation. In the context condition, the participants were first asked to retrieve a particular eventful or noneventful period in their life (e.g., WWII or retirement) before reporting particular memories from that period. In the no-context condition, in contrast, participants were asked to report memories with the corresponding properties - that is, eventful and noneventful memories - without retrieving a corresponding lifetime period first. The retrieval prompts (eventful and non- eventful) were sufficiently general to enable both younger and older adults to retrieve specific lifetime periods, as well as specific memories. Using this type of manipulation allows for accessing the facilitating effect of lifetime periods without utilizing additional personal history cues that are potentially highly associated to the particular lifetime periods chosen. Moreover, the eventfulness or noneventfulness of the lifetime period chosen cannot be used as an explanation for a facilitation through context if memory retrieval in the context condition is faster for these two very different periods, relative to retrieval without such a context. Thus, potential confounds regarding the definition of retrieval contexts were avoided.

In addition to investigating the facilitating effect of lifetime periods as retrieval cues for autobiographical memories, the present article examines a second mechanism that can be expected to play a role in autobiographical memory - namely, a selective retention mechanism that applies to the large pool of memories that are available in principle and, from these, selects particular memories that are kept accessible long term. This selective retention mechanism was assessed by having younger and older participants evaluate the memories they retrieved on aspects that may make these memories stand out relative to others, such as the landmark status and self-relevance of the events, their emotional valence (positive or negative), and their emotional intensity. The inclusion of older adults is relevant here because older adults have a larger pool of remote memories available for retrieval, relative to younger adults, which makes retention of these memories more difficult and effortful. A deeper insight into what characteristics retained memories from older adults have in common would provide valuable information about memory retention abilities across the life span, as well as about what social roles these memories may fulfill in old age.

Although recent studies of autobiographical memories have looked at retention of highly positive, important, and traumatic memories across the life span (Berntsen \& Rubin, 2002; Rubin \& Berntsen, 2003), no specific examination of the mechanism underlying this selective retrieval process and of how this may be different for younger and older adults has been conducted as of yet.

Studies on selective memory retention have shown that distinctive memory details that were associated with personally relevant themes provided faster access to specific information of a memory than did beginning and ending details of the memory (Anderson \& Conway, 1993). Other studies have demonstrated better retention of memories that were perceived as being life-changing events (landmark events) in adults with Alzheimer's disease (Fromholt \& Larsen, 1991) and of pleasant events over unpleasant events (Brewer, 1988; Wagenaar, 1986), especially when the information was highly self-relevant or self-important (Bellezza \& Hoyt, 1992; Thompson, Skowronski, Larsen, \& Betz, 1996). A study of autobiographical memory retrieval of vivid memories, in which younger and older adults were compared, suggested that older adults sample their memories from a pool of selfrelevant memories that they consider important (Cohen, 
1998; Cohen \& Faulkner, 1988). Berntsen and Rubin (2002) demonstrated that the content of important events retrieved was predominantly positive.

The results of these studies suggest better retention of positive events than of negative ones and better retention of landmark events or events that are self-relevant than of events that are less important for the person reporting them. It seems plausible to assume that these event characteristics contribute to the distinctiveness of the event, especially when the event is also emotionally salient. Thus, it seems that, mainly, those memories are kept accessible that possess characteristics that make them stand out relative to others. The assumption that distinct characteristics of memories are part of a selective retention mechanism has not been tested systematically as of yet.

Because older adults have a larger pool of memories to choose from and a more limited processing capacity to activate and retain these memories and probably have experienced a larger number of thematically similar events in different periods in their lives, one would expect that the distinctiveness of the original event is a more important factor for memory accessibility in older than in younger adults. The present study examines whether the respective memory characteristics are more common in memories of older adults relative to those of younger ones.

We hypothesize that older adults report more landmark events, more positive memories, and memories with higher relevance and emotional intensity ratings than do younger adults as a result of a selective retention mechanism that renders older adults more vulnerable to the forgetting of memories lacking these distinctive properties. The selective retention mechanism employed by older adults is the result of a processing-capacity-based necessity to reduce the large pool of remote and recent memories of similar experiences to a more manageable set of memories that can be retrieved despite the potentially larger constraints on older adults' cognitive capacity.

An alternative explanation for a relatively larger proportion of memories with distinctive properties in older adults is also possible, however. It could be that older adults simply have had more life-changing experiences, as compared with younger adults, and retain and report these experiences merely as the result of a larger availability of these kinds of events. In that case, younger adults do not report these kinds of life-changing events, because they have not had a chance to experience them yet. Both explanations will be examined in further detail on the basis of two experiments.

To summarize, we postulate that access to specific autobiographical events is mediated by two factors. The first factor is context. Access to specific events will be facilitated if these events are retrieved within the more general context of an eventful or noneventful lifetime period. Context should facilitate access to memories for both younger and older adults, since it provides a thematic and temporal framework with links to specific events. Differences between younger and older adults can be expected to become apparent in the more effortful retrieval of memories for older adults, who have a greater number of remote and competing memories to choose from and whose cognitive resources are more limited than those of younger adults (Holland \& Rabbitt, 1990). The second factor pertains to the type of memory that is being retrieved. Because it is impossible for older adults to avoid forgetting some of the events they have experienced in their lives, they can be expected to use (possibly without conscious awareness) retention strategies that allow certain memories to be retained and other memories to be forgotten. It can be assumed that the autobiographical memories most likely to be retained are distinctive memories that serve certain functions in their lives, such as contributing to a person's self-identity or being part of shared stories from the past with others, as well as providing experiences that can be used in the future to deal with new but similar situations (Cohen, 1998). Thus, we hypothesize that memories that stand out relative to others by having distinct components are most likely to be retained.

The following predictions were assessed in two experiments: (1) Younger and older adults should have shorter retrieval times for memories generated within the context of a lifetime period, as compared with memories generated outside such a context; (2) retrieval of autobiographical memories should be more effortful for older adults, resulting in longer retrieval times, relative to those of younger adults; and (3) older adults should generate autobiographical memories that are more likely to include landmark events, positive events, and events with higher emotional intensity and self-relevance ratings, relative to the memories of younger adults.

\section{EXPERIMENT 1}

\section{Method}

Participants. Sixty-two younger and 51 older adults participated in the experiment. The younger adults were undergraduates at Florida State University, participating for course credit. The older adults were part of a participant pool of older community-dwelling adults in Tallahassee. They received $\$ 10$ for their participation in a two-session experiment (the results of the second session on memory retention are reported in Dijkstra \& Kaup, 2003). Of the younger adults, $73 \%$ were White, $15 \%$ African-American, and $12 \%$ Hispanic; $58 \%$ were women. Their mean age was 20.8 years $(S D=2.7)$. Of the older adults, $98 \%$ were White, and 2\% African-American; 63\% of the older population were women. Their mean age was 71.6 years $(S D=7.1)$.

Equipment. The experiment was run on a PC using the E-Prime 1.0 software (Schneider, Eschman, \& Zuccolotto, 2002).

Design. The design for assessing the effect of context on the response time for memory retrieval was a mixed (task as a withinsubjects and condition as a between-subjects) factorial design. The design for assessing age differences with regard to distinctive properties of the originally experienced events was a nonequivalent groups design. The context group was instructed to retrieve autobiographical memories within the context of a lifetime period, whereas the no-context group was asked simply to retrieve autobiographical memories. In addition, all the participants were instructed to retrieve vivid memories (memories that stand out) as a separate task, without relation to a lifetime period.

Procedure. The participants in the no-context group were asked to retrieve two eventful memories (memories of unusual events), two noneventful memories (memories of usual, routine events), two 
vivid memories, and four cue word memories (memories related to a certain word, such as friend). The order of the memory tasks was counterbalanced across participants in the no-context condition. The participants in the context condition were asked to report an eventful period prior to retrieving two specific memories from that period, followed by two cue words. They were also asked to report a noneventful period prior to retrieving two specific memories from that period, followed by two cue words. In addition, they were asked to report two vivid memories. The order of the memory tasks was counterbalanced across participants within the context condition. The instructions for the participants are listed in Appendix A. Examples of the memories reported are listed in Appendix B.

The participants typed their autobiographical memories on a computer in a text box displayed on the monitor. The time between the space bar press when the participant started retrieval and the space bar press when he or she began to type in the memory was calculated as the response time for each memory. The space allowed for each memory was 270 characters (approximately four sentences). After a memory had been typed in, the experimenters asked the participants their age at the time of the event, as well as their ratings of these memories for landmark status (yes/no), self-relevance (on a scale from 1 to 5), positive, negative, or neutral emotional valence, and intensity of the emotional valence (on a scale from 1 to 5). Landmark events were characterized as events that were considered to have brought about a major change in the participant's life, such as awards, accidents, or graduations (Conway, 1992; Fromholt \& Larsen, 1991). The relevance of a memory reflected the impact of the memory on the participant's life (with 1 indicating no impact and 5 indicating high impact).

The experiment took between 15 and $45 \mathrm{~min}$ for the younger adults and between 15 and $55 \mathrm{~min}$ for the older adults.

\section{Results}

To assess the facilitation with which memories were accessed with and without a context, means and standard deviations of response times (RTs) per memory task were calculated. Due to a computer error, the cue word data for 17 younger adults (out of a total of 111 participants) were not recorded. Those data were considered missing data in the data set. Table 1 shows the RTs for the participants in the context and no-context conditions.

A 3 (task) $\times 2$ (condition) analysis of variance (ANOVA) was conducted to assess differences in RTs between the context and the no-context conditions for the different tasks. A main effect of condition was expected, indicating shorter RTs for the context group than for the nocontext group for eventful, noneventful, and cue word memories. The alpha level was set at .05. There were no main effects $(F<1)$ but there was a task $\times$ condition interaction $\left[F(2,188) 5.11, M S_{\mathrm{e}}=48.92, p<.01\right]$. Subsequent $t$ tests showed shorter RTs in the context than in

Table 1

Mean Response Times (in Seconds, With Standard Deviations) for Memory Retrieval in Experiment 1

\begin{tabular}{lrrrrr}
\hline & \multicolumn{2}{c}{ No Context } & & \multicolumn{2}{c}{ Context } \\
\cline { 2 - 3 } \cline { 5 - 6 } \multicolumn{1}{c}{ Memory Task } & $M$ & $S D$ & & $M$ & $S D$ \\
\hline Eventful & 11.0 & 9.9 & & 6.8 & 5.9 \\
Noneventful & 10.8 & 8.8 & & 7.3 & 5.7 \\
Vivid & 9.4 & 8.1 & & 7.7 & 6.4 \\
Cue word & 7.4 & 7.0 & & 10.2 & 7.7 \\
\hline
\end{tabular}

Note $-n=57$ for the no-context condition; $n=56$ for the context condition. the no-context condition for eventful memories $[t(91)=$ 2.72, $p=.008$, equal variances not assumed] and for noneventful memories, $[t(96)=2.49, p=.014$, equal variances not assumed], but not for cue word memories. In this task, RTs were numerically shorter in the no-context than in the context condition, although this effect was not significant $[t(94)=1.81, p=.073]$. No differences in the context/no-context conditions were expected for the vivid memory task, since context was manipulated only for the eventful, noneventful, and cue word memories. No difference in RT for vivid memories was indicated by $t$ tests $[t(111)=1.25, p=.211]$.

Age differences in retrieval time as a possible indication of more effortful retrieval of memories by older adults was assessed by a 4 (task) $\times 2$ (age group) ANOVA. Means for retrieval time per task per age group are presented in Table 2. There was no main effect of age group or task $(F<1)$, but there was a significant task $\times$ age group interaction $\left[F(3,282)=3.66, M S_{\mathrm{e}}=46.53, p=\right.$ $.013]$. Independent sample $t$ tests indicated shorter retrieval times for younger than for older adults for cue word memories $[t(94)=2.33, p=.022$, equal variances not assumed] and a corresponding trend for eventful memories $[t(111)=1.93, p=.056$, equal variances not assumed]. No differences in retrieval time were observed for noneventful memories $[t(111)=0.35, p=.724]$ and vivid memories $[t(111)=0.85, p=.400]$.

Age-related differences with respect to the distinctive properties of the originally experienced events were assessed by calculating for each participant the percentage of landmark events per memory task, the mean rating of self-relevance per memory task, the percentage of memories with positive, negative, and neutral valence per memory task, and the mean ratings of emotional intensity per memory task. The means of these measures across tasks are displayed in Table 3.

Independent sample $t$ tests were conducted to assess age differences for these distinctive properties. Older adults showed a higher proportion of landmark events $[t(110)=2.06, p=.041]$, higher self-relevance of events $[t(110)=4.28, p<.001]$, and higher intensity of emotion $[t(111)=7.37, p<.001]$ than did younger adults. Independent sample $t$ tests revealed a significantly higher occurrence of positively rated memories, as well as a significantly lower occurrence of negatively or neutrally rated memories, in older than in younger adults [positive, $t(111)=6.90, p<.001$; negative, $t(111)=3.60, p<$ .001 ; neutral, $t(111)=5.46, p<.001$, equal variances not assumed].

\section{Discussion}

We predicted that the context condition would yield shorter RTs than would the no-context condition for younger and older adults. The results mostly supported this hypothesis. RTs were shorter for the context condition, in which the participants described an eventful or noneventful period before retrieving memories from that period, than for the condition in which the participants retrieved eventful and noneventful memories without the 
Table 2

Mean Response Times (in Seconds, With Standard Deviations) for Memory Tasks in Younger and Older Adults in Experiment 1

\begin{tabular}{lccrrr}
\hline \multirow{2}{*}{\multicolumn{1}{c}{ Memory Task }} & $M$ & $S D$ & & \multicolumn{2}{c}{ Old } \\
\cline { 2 - 3 } \cline { 5 - 6 } Eventful & 7.60 & 6.3 & & 10.63 & 10.2 \\
Noneventful & 9.33 & 7.2 & & 8.82 & 8.3 \\
Cue word & 6.75 & 5.6 & 7.98 & 6.3 \\
Vivid & 9.17 & 8.2 & 10.21 & 8.5 \\
\hline
\end{tabular}

Note $-n=62$ for younger adults ( $n=45$ for cue word memories); $n=51$ for older adults.

context of a lifetime period. As was expected, no differences were found in RTs for vivid memories. Contrary to our expectations, however, no significant differences were found between context and no-context conditions for cue word memories. Possibly, the specificity of the cue, such as Friday or school, required a more elaborate search within the context of the lifetime period of events to match the constraints of the cue. Depending on the lifetime period chosen, events may not have taken place in that context that could be associated with a certain Friday or a certain event at school. For example, if the lifetime period chosen was WWII, no Friday or school memory may have stood out during this time, whereas other specific events from this eventful time period may have been readily available for retrieval. The fact that RTs for the cue word memory task were numerically shorter in the no-context condition than in the context condition corroborates this interpretation. If the particular lifetime period chosen does not contain a memory that is related to the particular cue word, the context condition can be expected to hinder memory retrieval, relative to the nocontext condition.

The second prediction concerned longer RTs for older adults, when autobiographical memories were retrieved, as an indication of more effortful retrieval from their pool of more remote and more plentiful memories. The results indicated longer retrieval times in older adults for memories with cue words, such as friend and Friday, and a corresponding trend for eventful memories, but no difference for noneventful and vivid memories. This result was unexpected. On the basis of the available data, we can only speculate about the reasons. One reason why noneventful memories may have been relatively easily acces-

Table 3

Mean Ratings/Proportions of Occurrence in Younger and Older Adults in Experiment 1

\begin{tabular}{lrrrrr}
\hline & \multicolumn{2}{c}{ Young } & & \multicolumn{2}{c}{ Old } \\
\cline { 2 - 3 } \cline { 5 - 6 } Property & $M$ & $S D$ & & $M$ & $S D$ \\
\hline Landmark & .53 & .25 & & .63 & .26 \\
Relevance & 3.33 & 0.73 & & 3.91 & 0.66 \\
Positive & .36 & .02 & & .62 & .03 \\
Negative & .40 & .02 & & .28 & .03 \\
Neutral & .24 & .01 & & .09 & .01 \\
Intensity & 2.84 & 0.74 & & 3.79 & 0.59 \\
\hline
\end{tabular}

Note $-n=62$ for younger adults; $n=51$ ( $n=50$ for eventful and noneventful memories) for older adults. sible for older adults is that the corresponding memories typically stemmed from more recent time periods (e.g., retirement), as compared, for instance, with eventful memories. One reason why we did not obtain age-related differences with respect to the RTs for vivid memories may, in fact, have something to do with the proposed selective retention mechanism, according to which older adults selectively retain memories with distinctive properties. It also seems possible that memory retrieval with cue words is more cognitively demanding than that with the other memory tasks, which may make the retrieval process particularly effortful for older adults.

The third prediction was related to the distinctive characteristics of the experienced events, such as the landmark status, self-relevance, emotional valence, and emotional intensity of the original experience. We hypothesized that older adults would report more landmark events, more positive memories, and memories with higher relevance and emotional intensity ratings than would younger adults. The results supported this prediction, suggesting that older adults are more likely to report memories of lifechanging events that are relevant and have high positive valence. This may be a function of a selective retention mechanism in which older adults forget memories that do not stand out as much, although an alternative explanation, according to which older adults simply have had more life-changing experiences than have younger adults, could also explain the results.

A way to examine this alternative explanation would be to conduct an experiment in which younger and older participants are instructed to retrieve autobiographical memories from a lifetime period that both groups had experienced, such as elementary school or a time period of 5 years ago. If older adults report memories with more distinctive components as a result of a spontaneous selective retention mechanism, they should report a higher proportion of landmark events for memories from elementary school and from 5 years ago. If older adults do not report a higher proportion of landmark events in memories from elementary school and from 5 years ago, the higher proportion of landmark events in eventful/ noneventful and vivid memories could be the result of older adults' experiencing events of this type during stages in their lives that younger adults have not experienced yet. Another, more subtle pattern could be that the remoteness of the original event (the difference between a person's current age and the time of the remembered event) mediates the likelihood that distinctive memories will be remembered. In that case, there should be a higher occurrence of (remote) landmark events in elementary school memories from older adults, as compared with that of younger adults, but this age difference would be absent for (less remote) memories from 5 years ago because the selective retention mechanism would not yet apply to these relatively recent memories.

The purpose of Experiment 2 was to replicate the findings from Experiment 1 with more generally chosen cue words for the context condition and with the addition of memory tasks prompting memories from elementary 
school and 5 years ago. In Experiment 2, we examined further whether a higher proportion of landmark events and positive/negative memories, as well as higher selfrelevance and emotional intensity ratings of memories in older adults, was due to a selective retention mechanism that they employ or simply to a larger likelihood of experiencing these events in their longer life span, as compared with younger adults. The participants were asked to report memories from two periods that both younger and older adults have experienced-elementary school and 5 years ago - and to evaluate the distinctive properties of these memories. Differences in the proportion of distinctive properties and ratings of self-relevance and emotional intensity between younger and older adults for these time periods could then be considered to be the result of a selective retention mechanism in older adults.

Changing the cue words allowed us to examine a potential facilitation of context for cue word memories. The addition of memory tasks tapping into time periods experienced by both younger and older adults enabled us to answer the question of whether a higher occurrence of landmark events in the memories of older adults was due just to their life experience or to the remoteness of the memories.

\section{EXPERIMENT 2}

\section{Method}

Participants. Two groups participated, 79 younger and 64 older adults. The younger adults were undergraduates at Florida State University, participating for course credit. The older adults were part of a participant pool of older community-dwelling adults in Tallahassee. They received $\$ 20$ for their participation in a twosession experiment (the results of the second session on memory retention are reported in Dijkstra, 2004). Of the younger adults, $73 \%$ were White, $17 \%$ African-American, 5\% Hispanic, 3\% Asian, and $2 \%$ other or multiracial; $81 \%$ were women. Their mean age was 18.6 years $(S D=1.5)$. Of the older adults, $92 \%$ were White, $3 \%$ African-American, 2\% Hispanic, 2\% Asian, and 1\% other or multiracial; $65 \%$ of the older population were women. Their mean age was 71.8 years $(S D=6.6)$.

Equipment. The experiment was run on a PC using E-Prime 1.0 software (Schneider et al., 2002).

Design. The design was identical to that in Experiment 1. The context group was instructed to retrieve autobiographical memories within the context of a lifetime period, whereas the no-context group was simply asked to retrieve autobiographical memories. One eventful memory and one noneventful memory were retrieved in this experiment (as compared with two in Experiment 1), as well as four cue word memories (house, car, visit, and friend). Instead of vivid memories, a memory from elementary school and a memory from 5 years ago were retrieved.

Procedure. The participants in the no-context group were asked to retrieve one eventful and one noneventful memory, four cue word memories, a memory from elementary school, and a memory from 5 years ago. The cue words Friday and school were replaced by house and car in order to impose fewer restrictions on retrieval from the chosen lifetime period. The participants in the context condition would report an eventful/noneventful period prior to retrieving one specific memory from that period, followed by two cue words. The elementary school memory and the memory from 5 years ago were retrieved either before or after the eventful and noneventful memories in the context condition and in random order in the no-context condition. The instructions for the additional memory tasks are listed in Appendix A. Examples of memories reported are listed in Appendix B. The experiment took between 15 and $45 \mathrm{~min}$ for the younger adults and between 15 and $50 \mathrm{~min}$ for the older adults.

The procedure was otherwise identical to that in Experiment 1. Data for 1 older adult were removed from the data set because this participant had great difficulty remembering the instructions of pressing the space bar before writing down the memories on the computer, which made her space bar presses unreliable as a measure of RT.

\section{Results}

To assess the facilitation with which memories are accessed with and without a context, means and standard deviations of RTs per memory task were calculated. Table 4 shows the RTs for the participants in the context and no-context conditions, as well as the RTs for memories from elementary school and 5 years ago.

A 3 (task) $\times 2$ (condition) ANOVA was conducted to assess differences in RTs between the context and the nocontext conditions for the different tasks. A main effect of condition was expected, indicating shorter RTs for the context group than for the no-context group for eventful, noneventful, and cue word memories. The alpha level was set at .05 . There was a main effect of condition $[F(1,139)=$ 4.77, $\left.M S_{\mathrm{e}}=394.13, p<.05\right]$ and a task $\times$ condition interaction, $\left[F(2,138)=7.08, M S_{\mathrm{e}}=123.07, p<.01\right]$. Subsequent $t$ tests indicated significant differences between the context and the no-context conditions, with shorter RTs for eventful memories $[t(98)=2.24, p=.027$, equal variances not assumed] and noneventful memories in the context than in the no-context condition $[t(83)=$ $2.51, p=.014$, equal variances not assumed], but no difference for cue word memories $[t(139)=0.487, p=$ .621]. No differences in RTs were expected between conditions for the elementary school memory or for the memory from 5 years ago, since these memories were generated separately and this was supported by the results $[t(139)=0.741, p=.460$, and $t(139)=0.788, p=$ .432 , respectively].

Mean RTs for the memory tasks in younger and older adults are presented in Table 5. A 5 (task) $\times 2$ (age group) ANOVA was conducted to examine the predicted greater effort of memory retrieval in older adults. This analysis revealed a main effect of age group $[F(1,139)=11.10$, $\left.M S_{\mathrm{e}}=495.97, p=.001\right]$ and a main effect of task $\left[F(4,556)=9.93, M S_{\mathrm{e}}=185.03, p<.001\right]$, but no task $\times$ age group interaction $\left[F(4,556)=1.80, M S_{\mathrm{e}}=185.03\right.$, $p=.127]$. Independent sample $t$ tests comparing RTs for

Table 4

Mean Response Times (in Seconds, With Standard Deviations) for Memory Retrieval in Experiment 2

\begin{tabular}{lrrrrr}
\hline & \multicolumn{2}{c}{ No Context } & & \multicolumn{2}{c}{ Context } \\
\cline { 2 - 3 } \cline { 5 - 6 } Memory Task & \multicolumn{1}{c}{$M$} & $S D$ & & $M$ & $S D$ \\
\hline Eventful & 12.1 & 16.9 & & 7.1 & 8.0 \\
Noneventful & 15.2 & 26.5 & & 6.9 & 8.4 \\
Cue word & 8.4 & 9.5 & & 9.2 & 8.2 \\
Elementary school & 6.9 & 8.4 & & 7.9 & 8.3 \\
Five years ago & 14.9 & 20.7 & & 18.0 & 25.7 \\
\hline
\end{tabular}

Note $-n=70$ for the no-context condition; $n=71$ for the context condition. 
younger and older adults separately for the different memory tasks revealed no differences in RT for eventful memories $[t(139)=1.24, p=.218]$, a trend for shorter RTs in the younger group when noneventful memories were retrieved $[t(139)=1.76, p=.081$, equal variances not assumed], and shorter RTs in younger adults for cue words $[t(139)=3.97, p<.001$, equal variances not assumed], elementary school memories $[t(139)=2.26, p=$ .025 , equal variances not assumed], and memories from 5 years ago $[t(139)=2.72, p=.007$, equal variances not assumed].

Means for the distinctive properties of the original experience, such as landmark status, self-relevance, emotional valence, and emotional intensity across memory tasks, were calculated to assess age differences in their occurrence and ratings. The results are displayed in Table 6 .

Independent sample $t$ tests were conducted to assess age differences for memory properties across memory tasks. Older adults reported more landmark events than did younger adults, but this effect was not quite significant $[t(138)=1.82, p=.071]$. Significant age differences were obtained for the self-relevance ratings of events $[t(139)=3.10, p=.002]$, and emotional intensity $[t(139)=3.79, p<.001]$, with higher ratings for memories from older adults, relative to younger adults. Independent sample $t$ tests revealed a significantly higher occurrence of positively rated memories in older adults than in younger adults $[t(139)=3.37, p=.001]$, no age differences in the occurrence of negatively rated memories $[t(139)=1.55, p=.180]$, and a significantly higher occurrence of neutrally rated memories for younger than for older adults $[t(139)=2.07, p=.041]$.

To assess whether older adults reported more landmark events than did younger adults because of their greater likelihood of experiencing landmark events, independent sample $t$ tests were conducted on the proportion of landmark events reported for memories from elementary school and 5 years ago, respectively. The results demonstrated a significant difference between younger and older adults for the proportion of landmark events from elementary school, with older adults reporting a larger proportion of landmark events than younger adults $[M=$ $.53, S D=.50$, and $M=.29, S D=.45$, respectively; $t(121)=2.90, p=.004$, equal variances not assumed], suggesting a more selective retention of memories that

Table 5

Mean Response Times (in Seconds, With Standard Deviations) for Memory Tasks in Younger and Older Adults in Experiment 2

\begin{tabular}{|c|c|c|c|c|}
\hline \multirow[b]{2}{*}{ Memory Task } & \multicolumn{2}{|c|}{ Young } & \multicolumn{2}{|c|}{ Old } \\
\hline & $M$ & $S D$ & $M$ & $S D$ \\
\hline Eventful & 8.38 & 11.2 & 11.19 & 15.7 \\
\hline Noneventful & 8.41 & 14.6 & 14.32 & 24.9 \\
\hline Cue word & 6.30 & 5.8 & 12.00 & 10.9 \\
\hline Elementary school & 6.06 & 6.0 & 9.22 & 10.3 \\
\hline Five years ago & 11.76 & 15.3 & 22.30 & 29.7 \\
\hline
\end{tabular}

Note $-n=78$ for young adults; $n=63$ for older adults.

\begin{tabular}{|c|c|c|c|c|}
\hline \multirow[b]{3}{*}{ Property } & \multicolumn{4}{|c|}{$\begin{array}{c}\text { Table } 6 \\
\text { Mean Ratings/Proportions of Occurrence } \\
\text { in Younger and Older Adults in Experiment } 2\end{array}$} \\
\hline & \multicolumn{2}{|c|}{ Young } & \multicolumn{2}{|c|}{ Old } \\
\hline & $M$ & $S D$ & $M$ & $S D$ \\
\hline Landmark & .51 & .22 & .59 & .26 \\
\hline Relevance & 3.42 & 0.75 & 3.80 & 0.67 \\
\hline Positive & .48 & .22 & .61 & .23 \\
\hline Negative & .26 & .22 & .21 & .20 \\
\hline Neutral & .26 & .17 & .19 & .17 \\
\hline Intensity & 3.06 & 0.84 & 3.61 & 0.89 \\
\hline
\end{tabular}

stand out in older adults, relative to younger adults. However, no difference in reported landmark events was found in memories from 5 years ago in younger and older adults $[t(135)=0.339, p=.735]$. Possibly, the remoteness of the original event mediated the likelihood that distinctive memories would be reported, with remote memories, such as those from elementary school, having a greater likelihood of containing distinctive properties than did those from 5 years ago.

To assess the role of remoteness of memories, a Pearson's correlational analysis was conducted on the following variables: the average remoteness of events across tasks (by subtracting the age at which a memory occurred from the participant's age) and the average ratings for landmark events, self-relevance, emotional valence, and intensity across tasks.

The matrix of correlations is presented in Table 7. The results showed positive relationships between remoteness and average occurrence of landmark events, selfrelevance ratings, emotional intensity ratings, and memories with positive valence. In other words, the remoteness of the memory reported was associated with the likelihood of memory retrieval of events that were landmark events, self-relevant events, and positive events, as well as emotionally intense events. Furthermore, distinctive properties, such as landmark status, self-relevance, emotional intensity and positive valence, were positively correlated with each other.

\section{Discussion}

The results demonstrated an effect of context, indicating that memory retrieval was faster when a lifetime period was accessed prior to retrieving a specific memory. This context effect was demonstrated for both the eventful and the noneventful periods. However, retrieval of cue word memories did not benefit from contextual support, despite the fact that more general cue words were chosen than in Experiment 1. Apparently, the facilitation of context for accessing specific memories from a lifetime period is restricted to memories from that context and should not be cued further with specific cue words. Cued recall may impose too many constraints on the search for memories that match the cue, whereas the experiences in the lifetime period do not necessarily contain cue-relevant information. This results in RTs that 
Table 7

Correlations Between Remoteness of Memories

and Memory Properties in Experiment $2(N=123)$

\begin{tabular}{|c|c|c|c|c|c|c|}
\hline & Landmark & Self-Relevance & Positive & Negative & Neutral & Intensity \\
\hline Remoteness & $.217^{*}$ & $.329^{* * *}$ & $.302^{* *}$ & -.125 & $-.205^{*}$ & $.352^{* * *}$ \\
\hline Landmark & 1 & $.616^{* * *}$ & $.263^{* *}$ & .046 & $-.378^{* * *}$ & $.529^{* * *}$ \\
\hline Self-relevance & & 1 & $.380^{* * *}$ & -.083 & $-.360^{* * *}$ & $.676^{* * *}$ \\
\hline Positive & & & 1 & $-.607^{* * *}$ & $-.430^{* * *}$ & $.592^{* * *}$ \\
\hline Negative & & & & 1 & $-.349^{* * *}$ & .083 \\
\hline Neutral & & & & & 1 & $-.785^{* * *}$ \\
\hline Intensity & & & & & & 1 \\
\hline
\end{tabular}

are as long as (but not longer than) RTs for cued recall without the context of a lifetime period.

As in Experiment 1, we did not find longer RTs with older than with younger adults across all the different memory tasks. In this experiment, however, the only task for which the age group effect was not significant was the eventful memory task, and even here a trend toward the expected age group difference emerged. In the light of these results, it seems unlikely that recency of experience was a valid explanation for why the noneventful memories were relatively accessible for older adults in Experiment 1. Rather, together with the results of Experiment 1 , the present results suggest that memory retrieval is more effortful for older adults when many aspects of the to-be-reported memory are specified by the experimenter, as was the case for cue word memories, but also for elementary school memories and memories from 5 years ago, where the experimenter specified the exact time period from which the reported memories were to be sampled.

With regard to the distinctive components of memories, the results indicated that older adults retrieved a greater number of positive memories and memories with higher self-relevance and emotional intensity ratings than did younger adults, who retrieved more memories with a neutral valence. Older adults also retrieved more landmark events than did younger adults, but this effect fell short of significance. When time periods for memory retrieval were held constant for younger and older adults (elementary school and 5 years ago), older adults tended to report more landmark events from elementary school than did younger adults, but not memories from 5 years ago. To some extent, retention of memories seems more selective, since distinctive memories are more likely to be retained by older adults. However, this pattern appears to be mediated by the remoteness of the memories retrieved, with reported memories from elementary school having a greater likelihood of containing distinctive properties in the reports of older adults than do memories from a period 5 years ago (see also Cohen \& Faulkner, 1988).

A remote memory that is still available for retrieval may be part of the "permastore" (Bahrick, 1984) collection of events, which are considered the most durable long-term memories. An alternative explanation for why remoteness mediates the likelihood that retrieved mem- ories will possess certain characteristics could be that older adults are more likely to frequently retrieve remote memories from the past, such as memories from elementary school, which may have made the events more accessible for retrieval and may also have resulted in higher ratings of self-relevance and emotional intensity. Several studies have demonstrated that recall of information facilitates subsequent recall even after relatively long delays (Thompson, Wenger, \& Bartling, 1978; Wenger, Thompson, \& Bartling, 1980).

\section{GENERAL DISCUSSION}

The results of two experiments consistently demonstrate that the retrieving of specific autobiographical memories is facilitated within the context of a lifetime period for younger and older adults. They support the results of studies that have shown faster access to memories when these are prompted with contextual retrieval cues, such as activities or lifetime periods (Conway \& Bekerian, 1987; Reiser et al., 1985). The experiments extend the findings of Conway and Bekerian by showing context effects of two different lifetime periods (eventful/noneventful) without utilizing personal history cues to prompt memory retrieval. Moreover, our results demonstrate similar context effects for older and younger adults. Finally, the results indicate that the context facilitation is highest under less constrained conditions of retrieval, such as an eventful or noneventful period, and lower within a cued retrieval context in which prompts, such as car or friend, are used. Along the same lines, more effortful retrieval of memories in older adults, resulting in RTs that are longer than those for younger adults, occurred under more constrained conditions of memory retrieval for cue word memories and for memories from elementary school and 5 years ago.

The results also show evidence for a differential retention mechanism in older and younger adults with regard to what memories are retrieved. With the same memory instructions, older adults are more likely to report landmark events, self-relevant events, positive events, and emotionally intense events than are younger adults. This result cannot be attributed to the fact that older adults are more likely to have experienced these events in their life, because older adults also reported more landmark events 
from elementary school than did younger adults, which is a period that both age groups had experienced for the same duration. Rather, it seems likely that older adults employ a retention mechanism for especially remote memories that stand out as very positive and self-relevant and distinct from other, more common events, whereas events that lack these characteristics may be forgotten.

Younger and older adults employ similar search strategies when retrieving memories from the past within or without the context of a lifetime period. The type of memories remembered is different, however. Older adults selectively remember more distinct events. These differences in age groups have not been examined in detail yet, but when examined in future studies, they could tell us more about the functions that autobiographical memories fulfill at any given time, as well as their possible growth in importance across the life span.

Possibly, autobiographical memories from specific events are part of the life narratives that contribute to the formation and preservation of a person's self-identity (Berntsen \& Rubin, 2002). These life narratives include a temporal order of experienced events, as well as goals that persons set out to achieve in life. As people get older and look back on their lives, they may evaluate whether they attained the goals that they set out to reach. They may selectively retain distinctive memories that fit the overall narrative and revolve around life-changing and self-relevant events better than they do memories that lack these characteristics. From this perspective, it is not surprising that remembered events tend to be more positive, because of the large number of events experienced in their lives and the need to integrate these experiences into the larger narrative of goal achievement. Alternatively, if autobiographical memories serve more of an interpersonal function, in which stories from the past are shared with others as part of everyday social interactions, it may be more pertinent to share memories of positive and relevant events than memories of negative ones or, at least, to limit the sharing of negative memories to very few memories. For both interpersonal and personal autobiographical memory functions, the selective retention of remote memories that include memories with distinctive components may enable older adults to maintain access to relevant parts of their past with minimal demands on their cognitive resources.

Our study has demonstrated the importance of examining autobiographical memories within the context in which they are generated. If memory retrieval is primed by a nonrestricted lifetime period, such as an eventful or noneventful lifetime period, the age of the person retrieving the memory does not matter, because memory retrieval will always be faster within such a context. Our findings also suggest that when retaining memories from the past, older adults employ a selective retention mechanism for memories with distinctive properties, especially for their most remote memories. More research should be conducted to examine a potential facilitation of rehearsal of memories for retrieval and to show to what extent and how retained memories become part of a person's life narrative.

\section{REFERENCES}

Anderson, S. J., \& Conway, M. A. (1993). Investigating the structure of autobiographical memories. Journal of Experimental Psychology: Learning, Memory, \& Cognition, 19, 1178-1196.

BAHRICK, H. P. (1984). Semantic memory content in permastore: Fifty years of memory for Spanish learned in school. Journal of Experimental Psychology: General, 113, 1-29.

Bellezza, F. S., \& Hoyt, S. K. (1992). The self-reference effect and mental cuing. Social Cognition, 10, 51-78.

Berntsen, D., \& RuBIN, D. C. (2002). Emotionally charged autobiographical memories across the life span: The recall of happy, sad, traumatic, and involuntary memories. Psychology \& Aging, 17, 636-652.

BREWER, W. F. (1988). Memory for randomly sampled autobiographical events. In U. Neisser \& E. Winograd (Eds.), Remembering reconsidered: Ecological and traditional approaches to the study of memory (pp. 21-90). New York: Cambridge University Press.

Burt, C. D., Kemp, S., \& Conway, M. A. (2003). Themes, events, and episodes in autobiographical memory. Memory \& Cognition, 31, 317-325.

CoHen, G. (1998). The effects of aging on autobiographical memory. In C. P. Thompson, D. J. Herrmann, D. Bruce, J. D. Read, D. G. Payne, \& M. P. Toglia (Eds.), Autobiographical memory: Theoretical and applied perspectives (pp. 105-124). Mahwah, NJ: Erlbaum.

Cohen, G., \& FaulKner, D. (1988). Life span changes in autobiographical memory. In M. M. Gruneberg, P. E. Morris, \& R. N. Sykes (Eds.), Practical aspects of memory: Current research and issues (Vol. 1, pp. 277-282). Chichester, U.K.: Wiley.

ConWAy, M. A. (1992). A structural model of autobiographical memory. In M. A. Conway, D. C. Rubin, H. Spinnler, \& W. A. Wagenaar (Eds.), Theoretical perspectives on autobiographical memory (pp. 167193). Dordrecht: Kluwer.

Conway, M. A., \& BeKerian, D. A. (1987). Organization in autobiographical memory. Memory \& Cognition, 15, 119-132.

Conway, M. A., \& Pleydell-Pearce, C. W. (2000). The construction of autobiographical memories in the self-memory system. Psychological Review, 107, 261-288.

DiJKstra, K. (2004, April). Facilitators in accessing autobiographical memories. Poster presented at the Cognitive Aging Conference, Atlanta.

Dijkstra, K., \& Kaup, B. (2003, June). Retrieval and discourse elements in autobiographical memories. Poster presented at the Eleventh Annual Society for Text and Discourse Conference, Madrid.

Fromholt, P., \& LARSEN, S. F. (1991). Autobiographical memory in normal aging and primary degenerative dementia (dementia of the Alzheimer type). Journals of Gerontology, 46, P85-P91.

Holland, C. A., \& RabBitT, P. M. A. (1990). Autobiographical and text recall in the elderly: An investigation of a processing resource deficit. Quarterly Journal of Experimental Psychology, 42A, 441-470.

Reiser, B. J., BlaCK, J. B., \& ABElson, R. P. (1985). Knowledge structures in the organization and retrieval of autobiographical memories. Cognitive Psychology, 17, 89-134.

Rubin, D. C., \& Berntsen, D. (2003). Life scripts help to maintain autobiographical memories of highly positive, but not highly negative, events. Memory \& Cognition, 31, 1-14.

Schneider, W., Eschman, A., \& Zuccolotto, A. (2002). E-Prime reference guide. Pittsburgh, PA: Psychology Software Tools.

Thompson, C. P., Skowronski, J. J., Larsen, S. F., \& Betz, A. L. (1996). Autobiographical memory. Remembering what and remembering when. Mahwah, NJ: Erlbaum.

Thompson, C. P., Wenger, S. K., \& Bartling, C. A. (1978). How recall facilitates subsequent recall: A reappraisal. Journal of Experimental Psychology: Human Learning \& Memory, 4, 210-221.

WagenaAr, W. A. (1986). My memory: A study of autobiographical memory over six years. Cognitive Psychology, 18, 225-252.

Wenger, S. K., Thompson, C. P., \& Bartling, C. A. (1980). Recall facilitates subsequent recognition. Journal of Experimental Psychology: Human Learning \& Memory, 6, 135-144. 
APPENDIX A

Instructions for Participants

Definition of autobiographical memories: I will ask you to recall memories from your life and write them down on the computer. You determine what memories to report, but they have to be descriptions of events you personally experienced and they have to be unique events that took place over a period of time, seconds, minutes, hours. It cannot be a recurring event, such as going swimming every day. Also, the description cannot be vague, such as "I saw my friend Jake yesterday," but should include a little bit of detail, for example "I ran into my friend Jake at the library, and we decided to go out for lunch together." This is also about the minimum length of a memory.

\section{Experiment 1}

\section{No-Context Condition}

These are the kinds of memories you will be prompted to recall:

- vivid memories: personal memories that really stand out in one way or another

- eventful memories: memories of unusual events.

-noneventful memories: everyday memories that are usual (but not recurring events)

- cue word memories: memories related to cue words, such as friend, school, visit.

\section{Context Condition}

- eventful period: describe one period in your life, including the age range, when a lot of things happened in your life and life was unpredictable, then give 2 specific memories from the eventful period. After this, you will be presented with 2 cue words, for example friend or Friday. You have to provide a memory based on that cue word from your eventful period.

noneventful period: describe one period in your life that was uneventful, life was routine and predictable, then give 2 specific memories from the noneventful period. Describe memories from that period based on 2 cue words, for example visit or school.

-vivid memories: personal memories that really stand out one way or another.

\section{Experiment 2}

Instructions were identical to those for Experiment 1, except that memories from elementary school and 5 years ago were retrieved instead of vivid memories.

- memory from elementary school: retrieve a memory of a specific event that happened in elementary school

- memory of five years ago: retrieve a memory of a specific event that happened five years ago.

\section{APPENDIX B}

Examples and Coding of Autobiographical Memories

\begin{tabular}{|c|c|}
\hline Memory Task & Memory \\
\hline Eventful memory & $\begin{array}{l}\text { After our IB exams were finished, the IB coordinator had to comply } \\
\text { with Leon County Schools and force us to go to class, even though we } \\
\text { were done with school. One day, all } 36 \text { of us decided to skip school } \\
\text { and go to a friend's house and there we ate, watched movies, etceteras. } \\
\text { The school had a fit. When we came back they gave us in school de- } \\
\text { tention and we had to sweep the entire school and pick up trash. }\end{array}$ \\
\hline Vivid memory & $\begin{array}{l}\text { When I was } 10 \text { years old, in the } 4 \text { th grade, there was a horrible tornado } \\
\text { in Cordele, GA, and I remember my daddy telling me to lie on the floor } \\
\text { with my baby brother and keep him quiet and my daddy standing by } \\
\text { the fireplace, praying. }\end{array}$ \\
\hline Cue word memory & $\begin{array}{l}\text { When I was learning to drive and this would have been, I was } 20 \text {. My } \\
\text { husband was teaching me how to drive, my first car, it was a standard } \\
\text { stick shift. We came to a railroad track and I slowed down, and I put it } \\
\text { in first, went across the tracks, put it in reverse and went back across } \\
\text { the railroad tracks. We have never forgotten that. }\end{array}$ \\
\hline
\end{tabular}

(Manuscript received June 7, 2004;

revision accepted for publication September 1, 2004.) 